
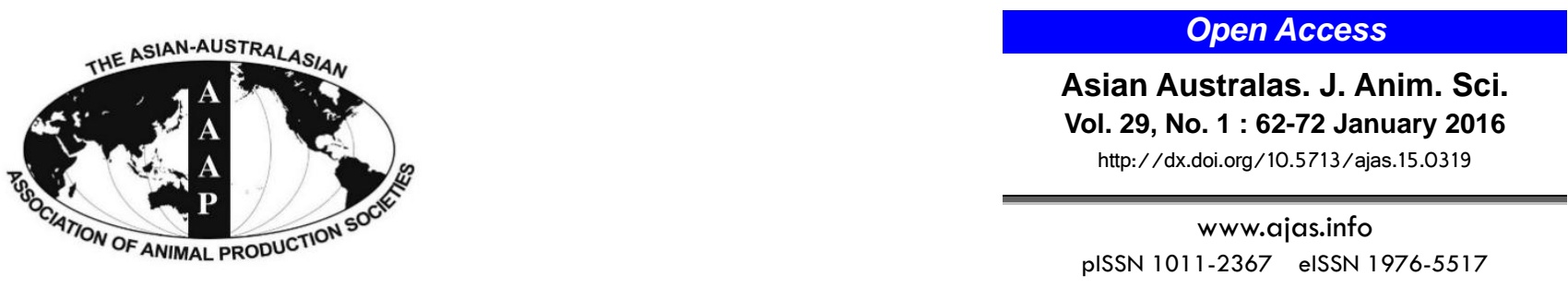

\title{
Dynamics Associated with Prolonged Ensiling and Aerobic Deterioration of Total Mixed Ration Silage Containing Whole Crop Corn
}

\author{
Huili Wang, Tingting Ning, Wei Hao, Mingli Zheng, and Chuncheng $\mathrm{Xu}^{*}$ \\ College of Engineering, China Agricultural University, Beijing 100083, China
}

\begin{abstract}
This study investigated the dynamics associated with prolonged ensiling and aerobic deterioration of whole crop corn (WCC) silages and total mixed ration (TMR) silages containing WCC (C-TMR silages) to clarify the differences that account for the enhanced aerobic stability of TMR silages. Laboratory-scale barrel silos were randomly opened after 7, 14, 28, and $56 \mathrm{~d}$ of ensiling and were subjected to analyses of fermentation quality, microbial and temperature dynamics during aerobic exposure. WCC and C-TMR silages were both well preserved and microorganisms were inhibited with prolonged ensiling, including lactic acid bacteria. Yeast were inhibited to below the detection limit of $500 \mathrm{cfu} / \mathrm{g}$ fresh matter within $28 \mathrm{~d}$ of ensiling. Aerobic stability of both silages was enhanced with prolonged ensiling, whereas C-TMR silages were more aerobically stable than WCC silages for the same ensiling period. Besides the high moisture content, the weak aerobic stability of WCC silage is likely attributable to the higher lactic acid content and yeast count, which result from the high water-soluble carbohydrates content in WCC. After silo opening, yeast were the first to propagate and the increase in yeast levels is greater than that of other microorganisms in silages before deterioration. Besides, increased levels of aerobic bacteria were also detected before heating of WCC silages. The temperature dynamics also indicated that yeast are closely associated with the onset of the aerobic deterioration of C-TMR silage, whereas for WCC silages, besides yeast, aerobic bacteria also function in the aerobic deterioration. Therefore, the inclusion of WCC might contribute to the survival of yeast during ensiling but not influence the role of yeast in deterioration of C-TMR silages. (Key Words: Total Mixed Ration, Silage, Aerobic Stability, Deterioration, Yeast)
\end{abstract}

\section{INTRODUCTION}

Aerobic deterioration is a critical problem affecting not only the nutritive value of feed but also the health of animals and humans (Woolford, 1990). Numerous studies have been conducted on silages to date and have reached some consensus regarding aerobic stability. According to these studies, not only fermentation products such as organic acids (Filya, 2003) and antifungal products (Wilkinson and Davies, 2013), but also yeast populations (particularly lactate-utilizing yeasts) observed at silo opening could influence the aerobic stability of silage (Woolford, 1990). The presence of yeasts is reported to be an indication of the initiation of aerobic deterioration

\footnotetext{
* Corresponding Author: Chuncheng Xu. Tel: +86-10-62736480, Fax: +86-10-62737997, E-mail: xucc@ cau.edu.cn Submitted Apr. 14, 2015; Revised Jun. 1, 2015; Accepted Jun. 8, 2015
}

because the growth of yeast often coincides with the heating of silages and the oxidization of the preserving acids that generally initiate aerobic spoilage. Besides, researches also indicate the role of bacteria (likely acid-tolerant bacteria) in the initial deterioration of whole crop corn (WCC) silages (Spoelstra et al., 1988).

WCC is regarded as an ideal crop for silage making due to its high yields, nutritive value, low buffering capacity and high water-soluble carbohydrates (WSC) content (McDonald, 1981). However, it is very prone to spoilage when exposed to air. It has been indicated that the aerobic stability could be greatly enhanced if formulated as total mixed ration (TMR) silage in comparison with ensiled alone (Nishino et al., 2003). There is also evidence that enhanced aerobic stability could be detected with prolonged ensiling, and yeast seemed to play less role in aerobic deterioration of TMR silages formulated with peach pomace, which had a high WSC content of $25.9 \%$ on dry 
matter (DM) basis (Hu et al., 2015). However, little information could be found for TMR silage, particularly regarding the mechanisms resulting in its enhanced aerobic stability compared with that of common silage. It is necessary to clarify the dynamics associated with aerobic deterioration of common silages and TMR silages to have a deep understanding on aerobic stability of TMR silages. Considering the enhanced aerobic stability of TMR silage with prolonged ensiling and the aerobically unstable WCC, this study was conducted on TMR silages inclusive of WCC. WCC silages were also used to reveal the dynamics associated with prolonged ensiling and aerobic deterioration of TMR silages containing WCC (C-TMR silages) and clarify the differences that account for the enhanced aerobic stability in TMR silages.

\section{MATERIALS AND METHODS}

\section{Silage materials and silage preparation}

The WCC and agro-industry by-products used in this study were all available local materials obtained from Hebei Province in China. WCC (Zhongke 11, a high yield corn) was harvested at the milk stage, chopped to a length of 2 to $3 \mathrm{~cm}$, formulated as a C-TMR by a TMR mixer (Labrador, Storti, Italy) and then ensiled within the day of production. The C-TMR was prepared using WCC, soybean curd residue, soy sauce residue, corn starch residue, rice bran, corn meal, alfalfa, cotton meal, wheat bran, soybean meal, and a vitamin-mineral supplement at a ratio of 20:10:2.5:9:27:10:8:5:4:2:2.5 on a DM basis. WCC and CTMR were packed tightly into high-density polyethylene barrels (60-L capacity), and each barrel was sealed with a polyethylene cover using a gasket fixed by a steel circlip. Triplicate barrels were randomly opened after 7, 14, 28, and $56 \mathrm{~d}$ of ensiling at ambient temperature.

\section{Chemical and fermentation quality analysis}

Non-fermented WCC and C-TMR samples were collected immediately after thorough mixing, and silage samples were collected at the time of silo opening and during the aerobic exposure periods. The DM content was determined by drying the material in an oven at $60^{\circ} \mathrm{C}$ for 48 $\mathrm{h}$ and grinding the dried material to pass through a $1-\mathrm{mm}$ screen. The DM, crude protein (CP) and crude ash were analysed according to methods 934.01, 976.05 and 942.05, respectively, of the AOAC (1990). The organic matter (OM) was calculated as the weight loss upon ashing. The acid detergent fiber (ADF) and neutral detergent fiber (aNDF) are analysed by the methods described by Van Soest et al. (1991) with amylase and sodium sulphite, and the results were expressed inclusive of residual ash. The WSC concentration was determined using the method of Owens et al. (1999).
The fermentation qualities were determined from water extracts of the silage. The $\mathrm{pH}$ was measured using a glass electrode $\mathrm{pH}$ meter (S20K, Mettler Toledo, Greifensee, Switzerland), and the organic acid content was determined by HPLC using the procedures described by $\mathrm{Xu}$ et al. (2007a).

\section{Microbial enumeration}

The numbers of microorganisms in the fresh material and silage samples were measured through the plate count method (Hu et al., 2015). Lactic acid bacteria (LAB) were counted from MRS agar prepared using MRS broth (Difco, Detroit, MI, USA) with $1.6 \%$ agar, after incubation in an anaerobic incubator at $35^{\circ} \mathrm{C}$ for $3 \mathrm{~d}$. The microbial counts for aerobic bacteria were determined on Nutrient Agar (Nissui, Tokyo, Japan), whereas for enterobacteria using Blue Light Broth (Nissui) with additional 1.6\% agar, and incubated at $30^{\circ} \mathrm{C}$ for $2 \mathrm{~d}$. Yeast were enumerated on spread plates of Potato Dextrose Agar (Nissui) that had been acidified to $\mathrm{pH} 3.5$ with sterilized tartaric acid. The plate cultures were incubated at $25^{\circ} \mathrm{C}$ for 3 to $5 \mathrm{~d}$. The colonies were counted from the plates at appropriate dilutions, and the number of colony forming units (cfu) is expressed per gram of fresh matter (FM).

\section{Aerobic stability test}

Non-fermented WCC and C-TMR were used as controls for comparing aerobic stability with the corresponding silages promptly after preparation. Silages ensiled for 7, 14, 28 , and $56 \mathrm{~d}$ were used for aerobic stability tests immediately following silo opening. After silo opening, the surface silage layers were removed, and the underlayers were scattered thoroughly. After emptying a silo, about 10 $\mathrm{kg}$ of the thoroughly mixed contents were placed loosely back into the barrel without compaction. A thermocouple thermometer (Datataker, Victoria, Australia) was inserted into the core of the sample mass to obtain temperature data. The changes in the ambient temperature and sample temperature were monitored every $10 \mathrm{~min}$, and the recording duration varied from 5 to $25 \mathrm{~d}$ depending on the extent of aerobic deterioration. All of the barrels were maintained at room temperature of approximately $20^{\circ} \mathrm{C}$ and partly covered to avoid water loss and allow air penetration.

The aerobic stability was distinguished by the length of time expended once the difference between the sample temperature and surrounding temperature reached $2^{\circ} \mathrm{C}$. Silage was considered to have deteriorated when its temperature was $2^{\circ} \mathrm{C}$ above the ambient temperature.

\section{Statistical analysis}

All of the microbial counts were $\log _{10}$-transformed to obtain normally distributed data and are presented on a wet basis. The counts that below the detection limit $(500 \mathrm{cfu} / \mathrm{g}$ 
Table 1. Changes in chemical components during ensiling of WCC and C-TMR silages

\begin{tabular}{|c|c|c|c|c|c|c|c|c|c|c|c|c|c|c|}
\hline \multirow{2}{*}{ Parameters } & \multicolumn{7}{|c|}{ WCC (d) } & \multicolumn{7}{|c|}{ C-TMR (d) } \\
\hline & 0 & 7 & 14 & 28 & 56 & SEM & Sig. & 0 & 7 & 14 & 28 & 56 & SEM & Sig. \\
\hline DM (g/kg FM) & $198^{\mathrm{a}}$ & $183^{\mathrm{b}}$ & $184^{\mathrm{b}}$ & $178^{\mathrm{bc}}$ & $176^{\mathrm{c}}$ & 2.11 & $<0.001$ & $444^{\mathrm{h}}$ & $428^{\mathrm{i}}$ & $428^{i}$ & $420^{j}$ & $425^{\mathrm{i}}$ & 2.21 & $<0.001$ \\
\hline $\mathrm{OM}$ & $931^{\mathrm{a}}$ & $930^{\mathrm{ab}}$ & $928^{b c}$ & $928^{b c}$ & $926^{c}$ & 0.59 & 0.001 & 902 & 901 & 901 & 901 & 901 & 0.29 & 0.611 \\
\hline DM) & $91.1^{\mathrm{c}}$ & $94.2^{\mathrm{bc}}$ & $98.2^{\mathrm{ab}}$ & $98.2^{\mathrm{ab}}$ & $102.3^{\mathrm{a}}$ & 1.12 & 0.001 & $142^{\mathrm{j}}$ & $144^{\mathrm{hij}}$ & $143^{\mathrm{ij}}$ & $145^{\mathrm{hi}}$ & $145^{\mathrm{h}}$ & 0.38 & 0.006 \\
\hline WSC (g/kg DM) & $144^{\mathrm{a}}$ & $32.3^{\mathrm{b}}$ & $31.4^{\mathrm{b}}$ & $26.1^{\mathrm{b}}$ & $29.2^{\mathrm{b}}$ & 12.2 & $<0.001$ & $63.2^{\mathrm{h}}$ & $27.3^{\mathrm{i}}$ & $27.2^{\mathrm{i}}$ & $26.6^{\mathrm{i}}$ & $29.5^{\mathrm{i}}$ & 3.82 & $<0.001$ \\
\hline aNDF (g/kg DM) & 522 & 520 & 515 & 520 & 508 & 2.53 & 0.497 & $464^{\mathrm{h}}$ & $445^{\mathrm{i}}$ & $437^{\mathrm{i}}$ & $433^{\mathrm{i}}$ & $431^{\mathrm{i}}$ & 3.49 & 0.001 \\
\hline $\mathrm{ADF}(\mathrm{g} / \mathrm{kg} \mathrm{DM})$ & $287^{\mathrm{c}}$ & $291^{\mathrm{bc}}$ & $308^{\mathrm{a}}$ & $309^{a}$ & $304^{\mathrm{ab}}$ & 2.79 & 0.003 & 275 & 273 & 272 & 271 & 269 & 1.38 & 0.751 \\
\hline
\end{tabular}

WCC, whole crop corn; C-TMR, total mixed ration containing whole crop corn; SEM, standard error of mean; Sig., significance; DM, dry matter; OM, organic matter; CP, crude protein; WSC, water-soluble carbohydrates; aNDF, neutral detergent fiber assayed with a heat stable amylase and expressed inclusive of residual ash; ADF, acid detergent fiber expressed inclusive of residual ash.

${ }^{\mathrm{a}-\mathrm{c}, \mathrm{h}-\mathrm{j}}$ Means within the same row with different superscript differ $(\mathrm{p}<0.05)$; Means of triplicate analyses.

FM) were assigned a value corresponding to half of the detection limit for subsequent statistical analysis. The fermentation characteristics, microbial counts, aerobic stability and chemical compositions during ensiling were statistically analysed by one-way analysis of variance followed by Tukey's test for the post hoc analysis using the IBM SPSS Statistics for Windows ver. 20.0 (IBM Co., Armonk, NY, USA). The statistical significance was set as $\mathrm{p}<0.05$.

\section{RESULTS}

\section{Characteristics of non-fermented WCC and C-TMR}

The chemical and microbial compositions of WCC and C-TMR prior to ensiling are shown in Table 1 and 2. The values for WCC are typical of graminaceous plants, with high WSC levels, a high moisture content and a low CP content. When incorporated into TMR, both the DM and CP contents improved. The microbial compositions of both WCC and C-TMR were detected at levels exceeding $10^{6}$ cfu/g FM, particularly for C-TMR.

\section{Fermentation quality and microbial and chemical components during ensiling}

Irrespective of ensiling periods, all of the silages were well-preserved with relatively low $\mathrm{pH}$ and high lactic acid content (Table 2). As observed for the main fermentation acids, lactic acid increased markedly within the first $7 \mathrm{~d}$ and reached peak values of $130 \mathrm{~g} / \mathrm{kg} \mathrm{DM}$ at day 28 post-ensiling for WCC silage and $86 \mathrm{~g} / \mathrm{kg} \mathrm{DM}$ at day 14 for C-TMR silage. Both the lactic and acetic acid (on DM basis) levels were higher in WCC silage than the acid levels in C-TMR silage during the same ensiling period, whereas, high ratio of lactic acid to acetic acid was detected in C-TMR silage. Furthermore, the ratio decreased significantly $(\mathrm{p}<0.001)$ with prolonged ensiling of WCC silages, whereas for $\mathrm{C}$ TMR silages, the ratio tended to increase with the extension of ensiling.

Microorganisms of both silages were inhibited to different extents. Yeast became undetected within $28 \mathrm{~d}$ of

Table 2. Changes in fermentation characteristics, microbial components and aerobic stability during ensiling of WCC and C-TMR silages

\begin{tabular}{|c|c|c|c|c|c|c|c|c|c|c|c|c|c|c|}
\hline \multirow{2}{*}{ Parameters } & \multicolumn{7}{|c|}{ WCC (d) } & \multicolumn{7}{|c|}{ C-TMR (d) } \\
\hline & 0 & 7 & 14 & 28 & 56 & SEM & Sig. & 0 & 7 & 14 & 28 & 56 & SEM & Sig. \\
\hline \multicolumn{15}{|l|}{ Fermentation characteristics } \\
\hline $\mathrm{pH}$ & $6.15^{\mathrm{a}}$ & $3.51^{b}$ & $3.58^{\mathrm{b}}$ & $3.60^{\mathrm{b}}$ & $3.58^{\mathrm{b}}$ & 0.28 & $<0.001$ & $5.04^{\mathrm{h}}$ & $4.05^{\mathrm{i}}$ & $4.04^{\mathrm{i}}$ & $4.03^{\mathrm{i}}$ & $4.03^{\mathrm{i}}$ & 0.11 & $<0.001$ \\
\hline Lactic acid (g/kg DM) & $2.32^{\mathrm{e}}$ & $117^{\mathrm{d}}$ & $128^{\mathrm{b}}$ & $130^{\mathrm{a}}$ & $123^{\mathrm{c}}$ & 13.1 & $<0.001$ & $13.6^{\mathrm{j}}$ & $75.2^{\mathrm{i}}$ & $86.0^{\mathrm{h}}$ & $79.3^{\mathrm{i}}$ & $78.7^{\mathrm{i}}$ & 7.15 & $<0.001$ \\
\hline Acetic acid (g/kg DM) & $0.31^{\mathrm{d}}$ & $26.0^{\mathrm{c}}$ & $33.9^{\mathrm{b}}$ & $42.9^{\mathrm{a}}$ & $43.9^{\mathrm{a}}$ & 4.26 & $<0.001$ & $4.02^{\mathrm{k}}$ & $16.3^{\mathrm{i}}$ & $19.2^{\mathrm{h}}$ & $15.1^{\mathrm{j}}$ & $15.3^{\mathrm{j}}$ & 1.39 & $<0.001$ \\
\hline Lactic acid/acetic acid ratio & - & $4.51^{\mathrm{a}}$ & $3.77^{\mathrm{b}}$ & $3.04^{\mathrm{c}}$ & $2.81^{\mathrm{d}}$ & 0.20 & $<0.001$ & - & $4.61^{\mathrm{i}}$ & $4.48^{\mathrm{i}}$ & $5.27^{\mathrm{h}}$ & $5.16^{\mathrm{h}}$ & 0.11 & $<0.001$ \\
\hline \multicolumn{15}{|l|}{ Microbial components } \\
\hline LAB $\left(\log _{10} \mathrm{cfu} / \mathrm{g} \mathrm{FM}\right)$ & $6.60^{c}$ & $8.80^{\mathrm{a}}$ & $7.69^{\mathrm{b}}$ & $7.68^{\mathrm{b}}$ & $6.23^{\mathrm{c}}$ & 0.25 & $<0.001$ & $9.47^{\mathrm{h}}$ & $8.50^{\mathrm{i}}$ & $8.36^{\mathrm{i}}$ & $8.12^{\mathrm{j}}$ & $5.65^{\mathrm{k}}$ & 0.34 & $<0.001$ \\
\hline Yeast $\left(\log _{10} \mathrm{cfu} / \mathrm{g} \mathrm{FM}\right)^{1}$ & $6.44^{\mathrm{a}}$ & $4.20^{\mathrm{b}}$ & $3.98^{b}$ & $2.40^{\mathrm{c}}$ & $2.40^{\mathrm{c}}$ & 0.40 & $<0.001$ & $7.71^{\mathrm{h}}$ & $3.36^{\mathrm{i}}$ & $3.28^{\mathrm{i}}$ & $2.40^{\mathrm{j}}$ & $2.40^{\mathrm{j}}$ & 0.53 & $<0.001$ \\
\hline Aerobic bacteria $\left(\log _{10} \mathrm{cfu} / \mathrm{g} \mathrm{FM}\right)$ & $7.79^{\mathrm{a}}$ & $4.91^{\mathrm{b}}$ & $4.67^{\mathrm{b}}$ & $4.72^{\mathrm{b}}$ & $4.59^{\mathrm{b}}$ & 0.33 & $<0.001$ & $8.36^{\mathrm{h}}$ & $6.13^{\mathrm{i}}$ & $6.03^{\mathrm{i}}$ & $6.09^{\mathrm{i}}$ & $5.84^{\mathrm{j}}$ & 0.25 & $<0.001$ \\
\hline Enterobacteria $\left(\log _{10} \mathrm{cfu} / \mathrm{g} \mathrm{FM}\right)^{1}$ & $6.65^{\mathrm{a}}$ & $2.40^{\mathrm{b}}$ & $2.40^{\mathrm{b}}$ & $2.40^{\mathrm{b}}$ & $2.40^{\mathrm{b}}$ & 0.45 & $<0.001$ & $7.35^{\mathrm{h}}$ & $2.40^{\mathrm{i}}$ & $2.40^{\mathrm{i}}$ & $2.40^{\mathrm{i}}$ & $2.40^{\mathrm{i}}$ & 0.53 & $<0.001$ \\
\hline Aerobic stability (h) & $5.5^{\mathrm{e}}$ & $31^{\mathrm{d}}$ & $55^{\mathrm{c}}$ & $100^{\mathrm{b}}$ & $144^{\mathrm{a}}$ & 13.3 & $<0.001$ & $5.0^{1}$ & $102^{\mathrm{k}}$ & $122^{\mathrm{j}}$ & $292^{\mathrm{i}}$ & $411^{\mathrm{h}}$ & 38.9 & $<0.001$ \\
\hline
\end{tabular}

WCC, whole crop corn; C-TMR, total mixed ration containing WCC; SEM, standard error of mean; Sig., significance; DM, dry matter; LAB, lactic acid bacteria; cfu, colony forming units; FM, fresh matter; Aerobic stability, was measured as hours to reach $2^{\circ} \mathrm{C}$ above ambient temperature.

${ }^{1} 2.40$, i.e., $\log _{10} 250 \mathrm{cfu} / \mathrm{g}$, microbial count below detection limit is assigned a value corresponding to half of the detection limit, numerically for one-way analysis of variance.

${ }^{\mathrm{a}-\mathrm{e}, \mathrm{h}-\mathrm{l}}$ Values in the same row with different superscript letters differ $(\mathrm{p}<0.05)$; Means of triplicate analyses. 
ensiling, whereas enterobacteria were not detected after less than seven days. Aerobic bacteria were also inhibited within $7 \mathrm{~d}$ of ensiling. In addition, LAB that were detected at high levels of over $10^{6} \mathrm{cfu} / \mathrm{g}$ in WCC and C-TMR, were also inhibited with prolonged ensiling. Significant differences were also detected in the chemical components, with the exception of the content of aNDF in WCC silages and the contents of $\mathrm{OM}$ and $\mathrm{ADF}$ in C-TMR silages, which remained stable throughout the ensiling periods. The OM content of WCC decreased with prolonged ensiling. The DM contents of both WCC and C-TMR silages decreased by approximately $20 \mathrm{~g} / \mathrm{kg}$ during the 56-d ensiling period and approximately $15 \mathrm{~g} / \mathrm{kg}$ occurred within the first $7 \mathrm{~d}$ of ensiling. The WSC in fresh WCC was consumed by more than $75 \%$, mostly during first $7 \mathrm{~d}$ of ensiling. The content of $\mathrm{CP}$ increased for both silages, and aNDF decreased with ensiling, particularly for C-TMR silage. The content of ADF increased in WCC silage, whereas in C-TMR, the content tended to decrease.

\section{Aerobic stability of WCC and C-TMR silages}

For non-fermented WCC and C-TMR, deterioration occurred within $6 \mathrm{~h}$ of aerobic exposure. However, the aerobic stability was greatly enhanced $(\mathrm{p}<0.001)$ with prolonged ensiling, particularly for C-TMR silages (Table 2). When the ensiling period was prolonged to $56 \mathrm{~d}$, WCC silage resisted deterioration for as long as $144 \mathrm{~h}$, whereas CTMR silage resisted deterioration for $411 \mathrm{~h}$. Overall, the aerobic stability of C-TMR silages were approximately two-fold greater than that of WCC silages during the same ensiling period.

Fermentation quality dynamics during aerobic exposure

The changes of fermentation quality in non-fermented WCC and C-TMR after exposure to air are shown in Figure 1. Similarities were observed during the first $24 \mathrm{~h}$ of exposure. During the initial $6 \mathrm{~h}$, both materials exhibited an increased lactic acid content and a reduction in $\mathrm{pH}$. After 24 $\mathrm{h}$ of exposure, the lactic and acetic acid in both WCC and $\mathrm{C}$-TMR started to decrease and were reduced to a lower level in WCC (until $120 \mathrm{~h}$ of exposure), whereas in C-TMR, the acid levels increased again after 48 or $72 \mathrm{~h}$ of exposure, and $\mathrm{pH}$ decreased accordingly from 7.1 to 5.8.

After silo opening, all of the silages experienced a longer and more stable period before silage heating $\left(2{ }^{\circ} \mathrm{C}\right.$ above room temperature) occurred. During the deterioration of WCC silages, all of the acids decreased throughout the detection periods, and the $\mathrm{pH}$ increased accordingly from 3.6 to levels above 7.0 (Figure 2). Similar tendency was also observed in C-TMR silages, which encountered a $\mathrm{pH}$ increase from 4.0 to above 6.7 after exposure (Figure 3). Thereafter, $\mathrm{pH}$ changes differed by ensiling periods. For the short-ensiled ( 7 and $14 \mathrm{~d}$ ) C-TMR silages, the $\mathrm{pH}$ decreases to levels below 6.0 and later increased again to higher levels. However, the long-ensiled (28 and 56 d) C-TMR silages encountered a $\mathrm{pH}$ increase throughout the deterioration periods, except for a likely decrease of $\mathrm{pH}$ in the 28-d CTMR silage (at $432 \mathrm{~h}$ ).

\section{Microbial dynamics during aerobic exposure}

The microbial dynamics of non-fermented WCC and CTMR after exposure are shown in Figure 4. Similar changes were detected in both materials. The yeast levels decreased during the first $6 \mathrm{~h}$, increased to higher levels until $48 \mathrm{~h}$ and then decreased again. Other microorganisms in C-TMR exhibited changes similar to those found for yeast during the first $24 \mathrm{~h}$. The microorganisms in WCC other than yeast exhibited an opposite trend during the first $12 \mathrm{~h}$ of exposure.

The microbial dynamics of WCC and C-TMR silages after aerobic exposure are shown in Figure 5 and 6 . The LAB counts of WCC silages mostly remained at approximately $10^{8} \mathrm{cfu} / \mathrm{g}$ FM before aerobic deterioration. However, the aerobic bacteria and yeast levels both increased before deterioration, particularly the yeast, which
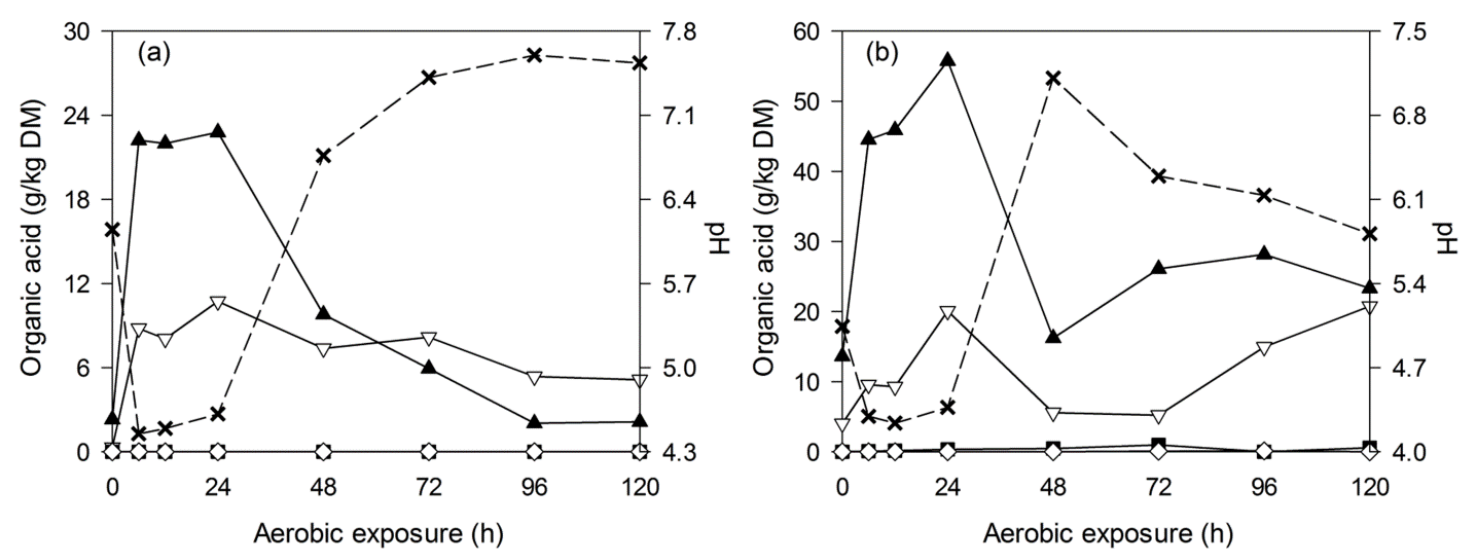

Figure 1. Changes in lactic acid $(\boldsymbol{\Lambda})$, acetic acid $(\nabla)$, propionic acid $(\boldsymbol{\bullet})$, butyric acid $(\diamond)$ and $\mathrm{pH}(\times)$ during aerobic deterioration of non-fermented WCC (a) and C-TMR (b). DM, dry matter; WCC, whole crop corn; C-TMR, total mixed ration containing WCC. 

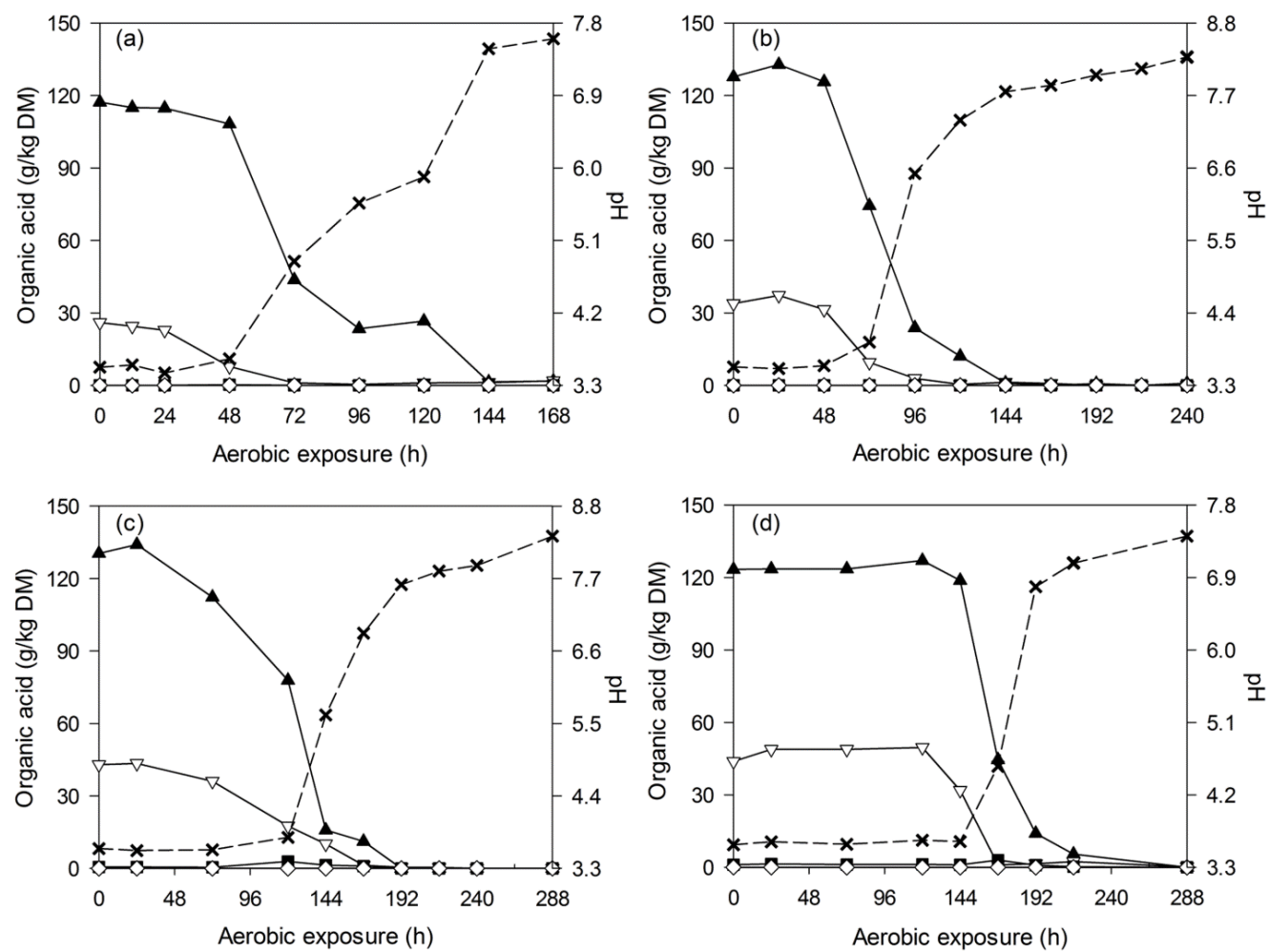

Figure 2. Changes in lactic acid $(\boldsymbol{\Delta})$, acetic acid $(\nabla)$, propionic acid $(\boldsymbol{\bullet})$, butyric acid $(\diamond)$ and $\mathrm{pH}(\times)$ during aerobic deterioration of WCC silages ensiled for 7 (a), 14 (b), 28 (c), and 56 d (d). DM, dry matter; WCC, whole crop corn.
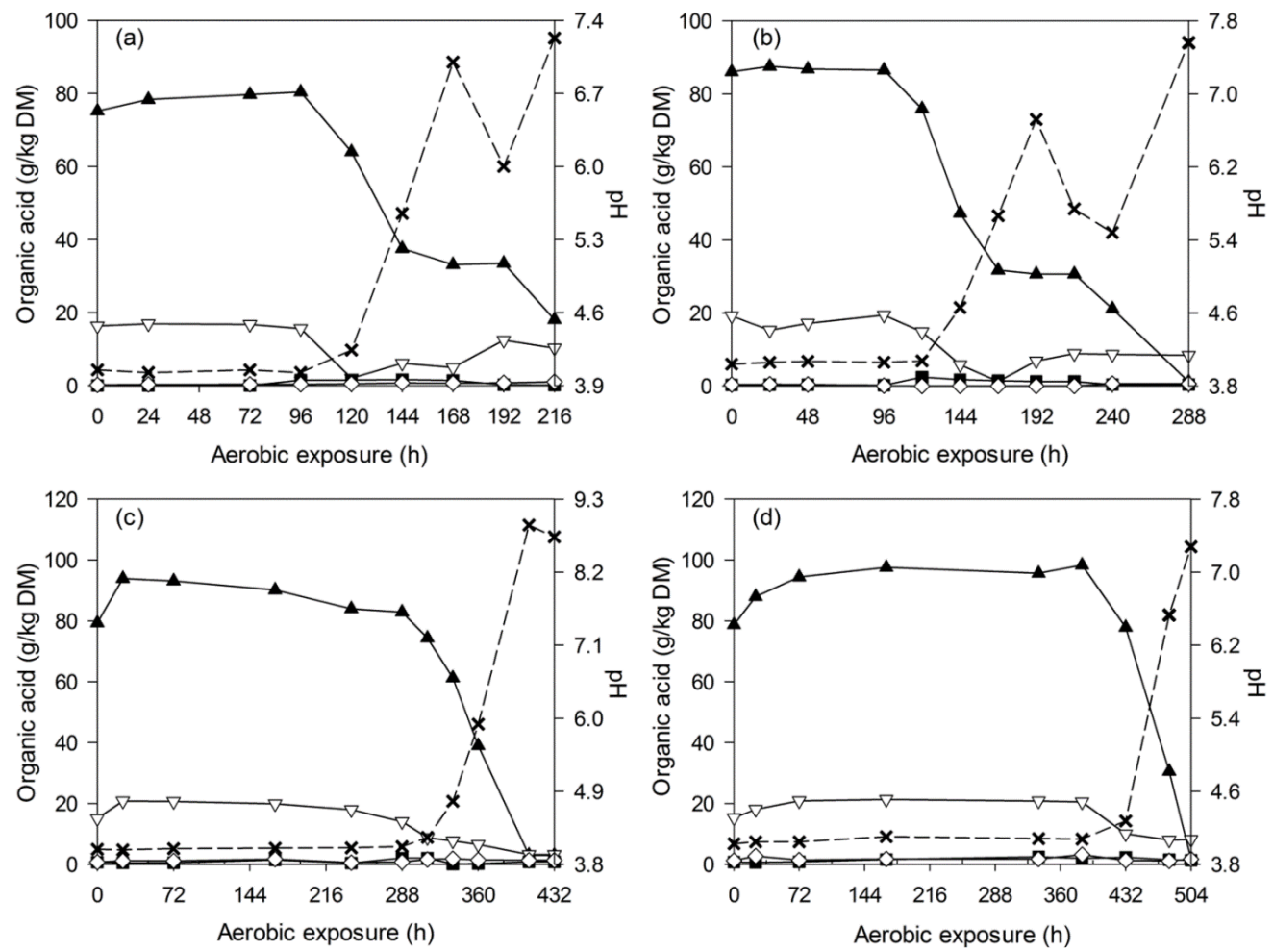

Figure 3. Changes in lactic acid $(\boldsymbol{\Delta})$, acetic acid $(\nabla)$, propionic acid $(\boldsymbol{\bullet})$, butyric acid $(\diamond)$ and $\mathrm{pH}(\times)$ during aerobic deterioration of $\mathrm{C}$ TMR silages ensiled for 7 (a). 14 (b). 28 (c). and 56 d (d). DM. drv matter: C-TMR. total mixed ration containing whole crop corn. 

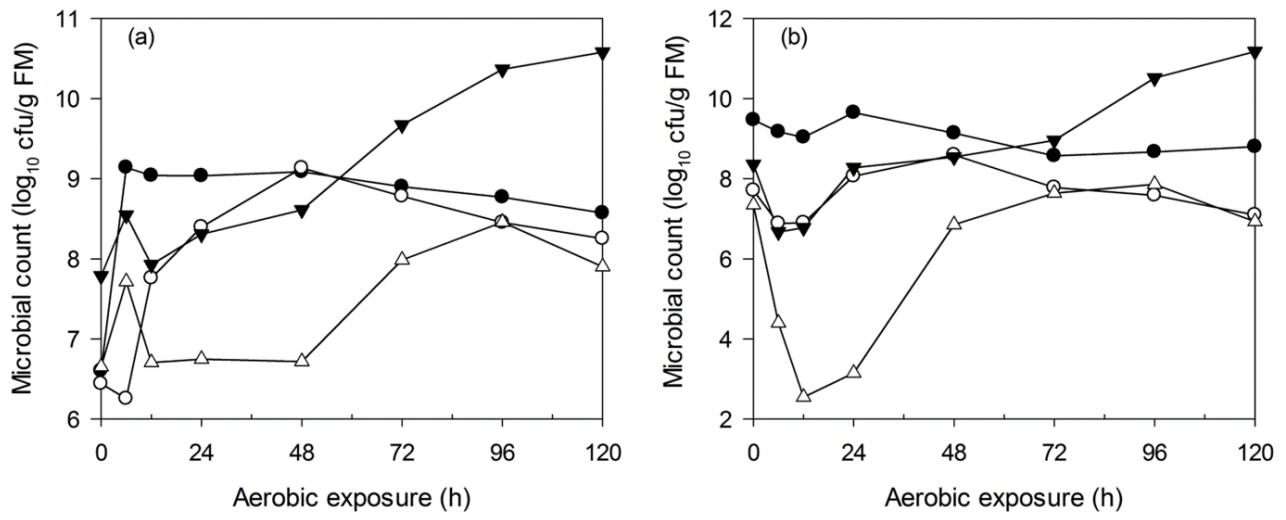

Figure 4. Changes in lactic acid bacteria $(\bullet)$, yeast $(\circ)$, aerobic bacteria $(\boldsymbol{\nabla})$ and enterobacteria $(\Delta)$ counts during aerobic deterioration of non-fermented WCC (a) and C-TMR (b). cfu, colony forming units; FM, fresh matter; WCC, whole crop corn; C-TMR, total mixed ration containing WCC.

exhibited a earlier and greater increase before aerobic deterioration. For WCC silages that were ensiled for 7, 14, 28 , and $56 \mathrm{~d}$, the maximum yeast counts (about $10^{8} \mathrm{cfu} / \mathrm{g}$ FM) occurred at about 72, 96, 120, and $168 \mathrm{~h}$ after exposure, respectively. Irrespective of ensiling periods, enterobacteria started to proliferate after deterioration. Similar results were found for C-TMR silages, irrespective of the ensiling periods. The yeast levels increased significantly before
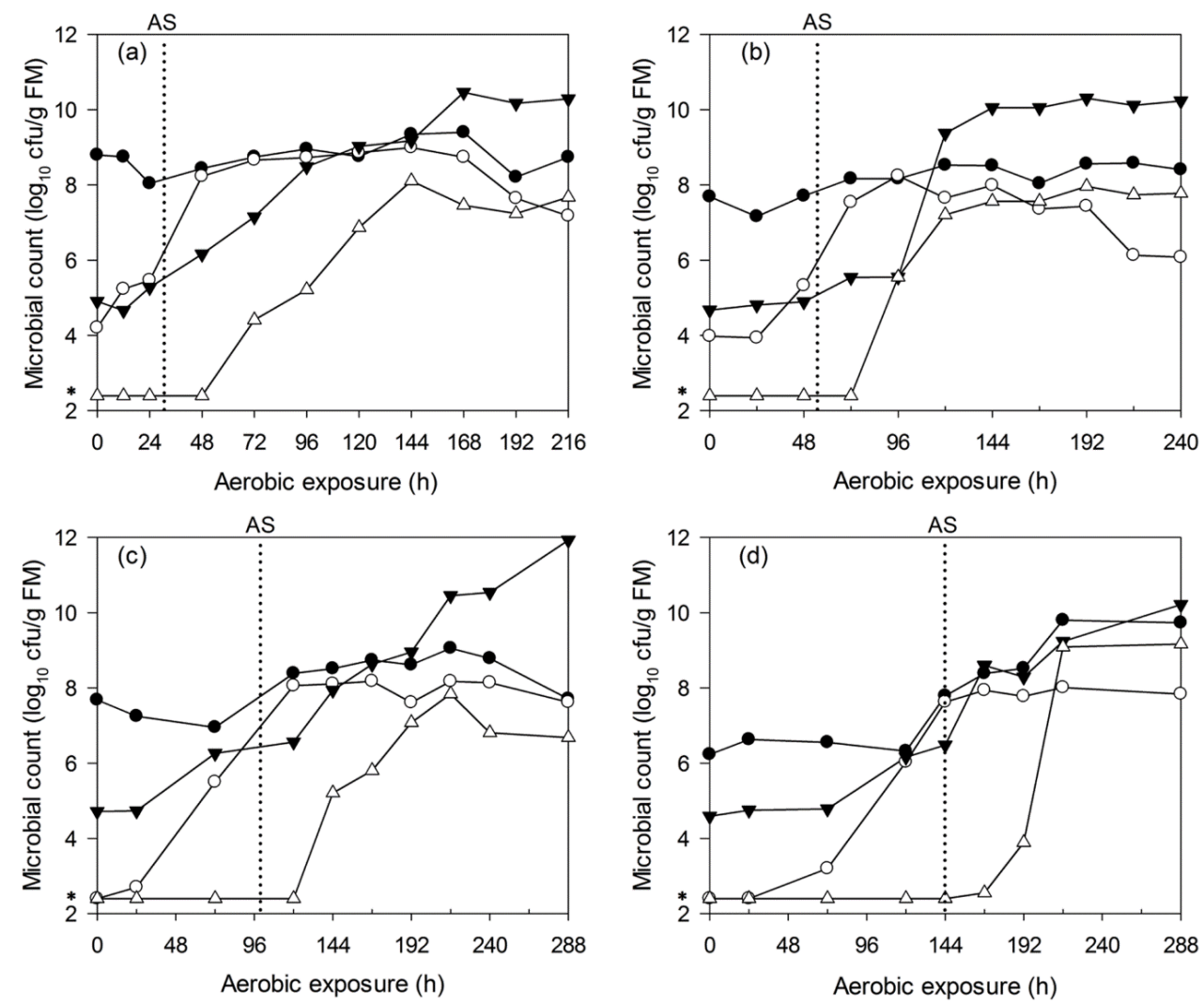

Figure 5. Changes in lactic acid bacteria $(\bullet)$, yeast $(\circ)$, aerobic bacteria $(\boldsymbol{\nabla})$ and enterobacteria $(\Delta)$ counts during aerobic deterioration of WCC silages ensiled for 7 (a), 14 (b), 28 (c), and 56 d (d). AS, aerobic stability; *, 2.40, i.e., $\log _{10} 250$ cfu/g, a microbial count below the detection limit was assigned a value corresponding to half of the detection level. The reported values represent the averages from triplicate analyses. cfu, colony forming units; FM, fresh matter; WCC, whole crop corn. 

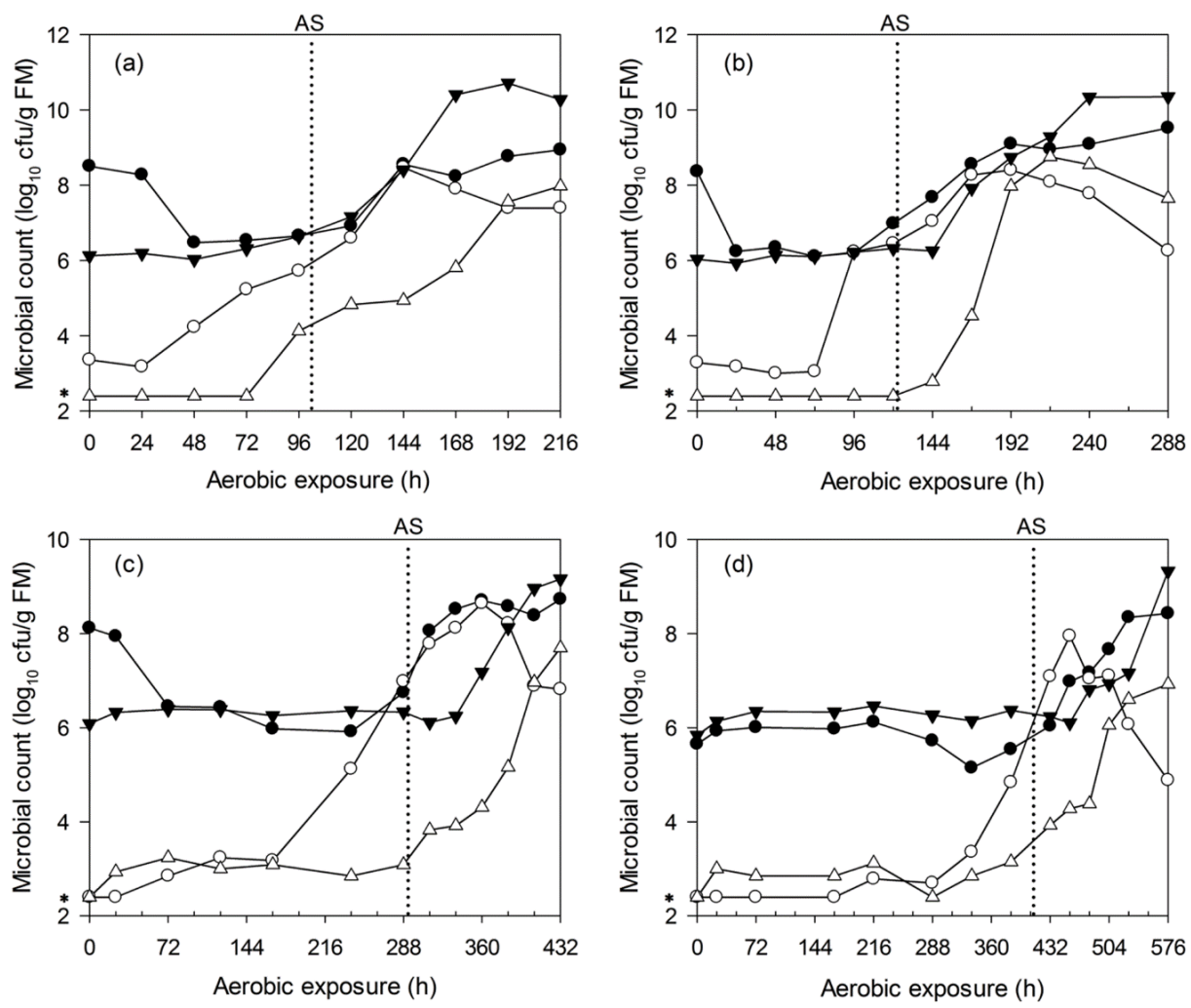

Figure 6. Changes in lactic acid bacteria $(\bullet)$, yeast $(\circ)$, aerobic bacteria $(\boldsymbol{\nabla})$ and enterobacteria $(\Delta)$ counts during aerobic deterioration of C-TMR silages ensiled for 7 (a), 14 (b), 28 (c), and 56 d (d). AS, aerobic stability; *, 2.40, i.e., $\log 10250$ cfu/g, a microbial count below the detection limit was assigned a value corresponding to half of the detection level. The reported values represent the averages from triplicate analyses. cfu, colony forming units; FM, fresh matter; C-TMR, total mixed ration containing whole crop corn.

of $10^{6} \mathrm{cfu} / \mathrm{g}$ FM before deterioration, which is similar to the level of aerobic bacteria. Aerobic bacteria counts were detected to increase in deteriorated C-TMR silages. Whereas, LAB and enterobacteria occasionally increased prior to deterioration but never before the proliferation of yeast.

\section{Temperature dynamics during aerobic exposure}

The temperature of non-fermented $\mathrm{WCC}$ and $\mathrm{C}-\mathrm{TMR}$ increased to $30^{\circ} \mathrm{C}$ within $6 \mathrm{~h}$ of exposure, reached $40^{\circ} \mathrm{C}$ after $9 \mathrm{~h}$ and $16 \mathrm{~h}$, respectively, and then remained above $40^{\circ} \mathrm{C}$ until the end of the monitoring period $(120 \mathrm{~h})$. WCC and C-TMR silages exhibited different temperature dynamics during aerobic exposure. Only one temperature peak was detected in WCC silages after exposure, ignoring the temperature variations caused by periodic mixing (Figure 7). The peak values of WCC silages ensiled for 7 , 14,28 , and $56 \mathrm{~d}$ were observed after about 128, 109, 162, and $166 \mathrm{~h}$ of exposure, respectively, which were varied from $48^{\circ} \mathrm{C}$ to $42^{\circ} \mathrm{C}$. However, two peaks were detected in $\mathrm{C}$-TMR silages during the monitoring periods, ignoring the periodic temperature variations (Figure 8 ). The first peak temperature of C-TMR silages ensiled for 7, 14, 28, and 56 $\mathrm{d}$ were detected at approximately 162, 173, 323, and $438 \mathrm{~h}$, respectively, and the peak values decreased from $54^{\circ} \mathrm{C}$ to $45^{\circ} \mathrm{C}$ with prolonged ensiling periods. Furthermore, the first temperature peak tended to be lower with the extension of ensiling, particularly C-TMR silages. The duration of the first heating was decreased with prolonged ensiling, especially for that of WCC silages. It is notable that the temperature minimum of C-TMR silages after the first peak was concomitant with a $\mathrm{pH}$ decrease for the short-ensiled silages, whereas with a $\mathrm{pH}$ increase for the long-ensiled CTMR silages, which has no $\mathrm{pH}$ decrease during the entire monitoring periods.

\section{DISCUSSION}

TMR silages incorporated with locally available byproducts and WCC obtained good fermentation quality and aerobic stability in this study. The result is consistent with our previous studies (Xu et al., 2007a,b; Hu et al., 2015), which indicated that high-moisture food by-products can be formulated as TMR silage. This may be attributed to the sufficient WSC contents in WCC and C-TMR (144 and $63.2 \mathrm{~g} / \mathrm{kg}$ ) to meet the requirement for obtaining wellpreserved silage (Smith, 1962). Therefore, good fermentation quality could be expected even though high numbers of aerobic bacteria and yeast were detected in nonfermented WCC and C-TMR. 

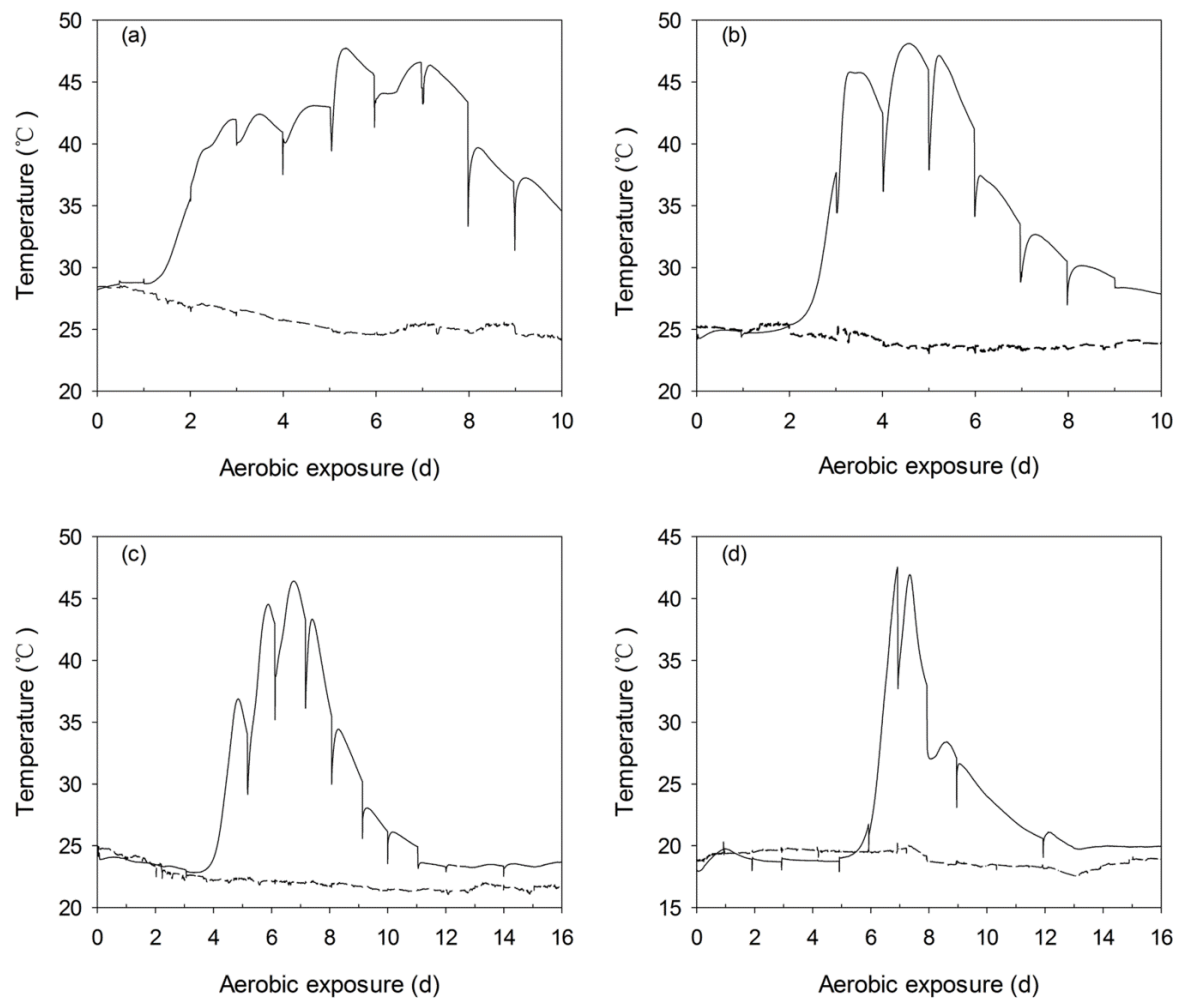

Figure 7. Changes in the core temperature (-) and ambient temperature (---) during the aerobic exposure of WCC silages ensiled for 7 (a), 14 (b), 28 (c), and $56 \mathrm{~d}$ (d). The reported values represent the averages from triplicate analyses. WCC, whole crop corn.
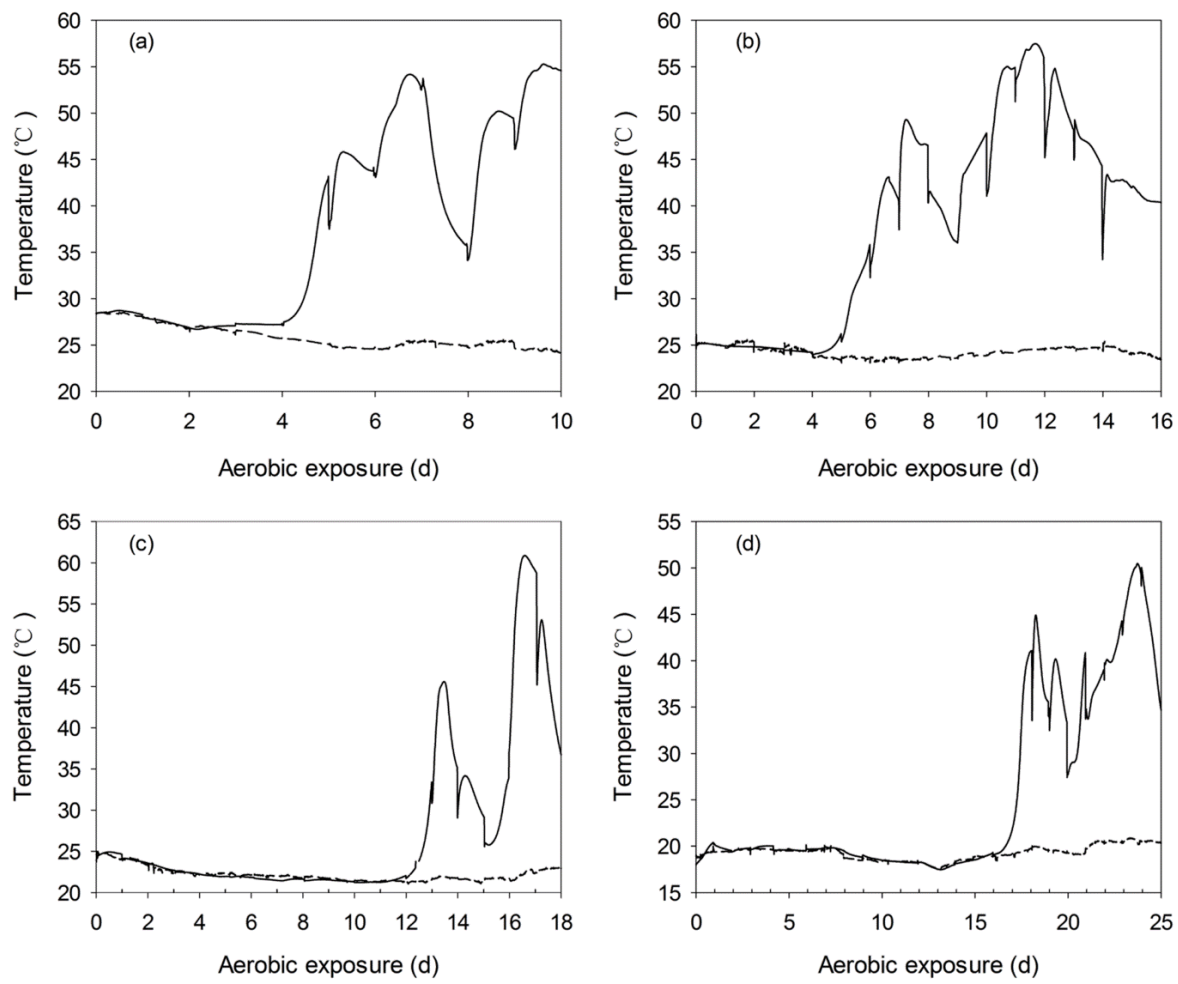

Figure 8. Changes in the core temperature (-) and ambient temperature (---) during the aerobic exposure of C-TMR silages ensiled for 7 (a), 14 (b), 28 (c), and $56 \mathrm{~d}$ (d). The reported values represent the averages from triplicate analyses. C-TMR, total mixed ration containing whole crop corn. 
It has been confirmed by many researches that yeasts are primarily responsible for the onset of the aerobic spoilage of silage (McDonald et al., 1991). In this study, the microbial dynamics of WCC and TMR silages after opening also verified the role of yeast in the initiation of deterioration, as indicated by the fact that yeast were the first to propagate and the increase in yeast levels is greater than that of other microorganisms in silages before deterioration. Besides, aerobic bacteria also played important role in the deterioration of WCC silages because increased levels of aerobic bacteria were also detected before heating. Moreover, the first temperature peak of $\mathrm{C}$ TMR silages almost coincided with the maximum yeast count, while for WCC silages, comparable numbers of aerobic bacteria and yeast were detected when the silages reached their temperature peak. Therefore, yeast probably initiated the deterioration of C-TMR silages, whereas for WCC silages, yeast and aerobic bacteria both functioned in aerobic deterioration. The results are inconsistent with previous studies on maize silages the first temperature peak is associated with the development of yeasts and aerobic acetic acid bacteria and the second temperature increase is a reflection of mold development (Wilkinson and Davies, 2013). The detection of high levels of aerobic bacteria in aerobically deteriorated WCC and C-TMR silages indicated the role of aerobic bacteria in the late deterioration, which agreed with the studies conducted by McDonald et al. (1991) and Seppala et al. (2013). Furthermore, enterobacteria played less role in silages with low $\mathrm{pH}$ as they were mostly observed in deteriorated silages. It is consistent with the results that enterobacteria do not proliferate and their viability decreases at $\mathrm{pH}$ values lower than 4.5 to 5.0 (Heron et al., 1993). Overall, multiple microorganisms contribute to the dynamic changes observed after aerobic exposure, and yeast were closely associated with the onset of aerobic deterioration of silages, particularly C-TMR silages.

In this study, the LAB of over $10^{6} \mathrm{cfu} / \mathrm{g}$ detected in fresh WCC and C-TMR contributed to good fermentation quality in silages, whereas for aerobic exposed WCC and CTMR, caused an accumulation of lactic acid, decrease in $\mathrm{pH}$ and inhibition of yeast at the initial period, however, coincided with a notable heat and followed by increased $\mathrm{pH}$. The properties (residue or meal) of TMR ingredients, which could easily form a relatively anaerobic condition after put back without compaction, might also account for the lactic acid fermentation. In this study, the microbial populations of WCC and C-TMR were all above $10^{6} \mathrm{cfu} / \mathrm{g}$ FM and deteriorated within $6 \mathrm{~h}$ of aerobic exposure. It is consistent with previous studies that silages with over $10^{5} \mathrm{cfu} / \mathrm{g}$ of yeast are prone to spoil when exposed to air $(\mathrm{McDonald}$ et al., 1991). With prolonged ensiling, the yeast counts fell below the detectable level, further improving the aerobic stability due to the absence of undesirable microorganisms. Similar results were also obtained in our previous study on TMR silages with different moisture contents (Hao et al., 2015), which also indicates that TMR silages with higher moisture content are relatively unstable (Hao et al., 2015). In this study, C-TMR silages were more aerobically stable than WCC silages for the same ensiling period. Besides the high moisture content, the weak aerobic stability in WCC silage is likely attributable to the high lactic acid content and high yeast count, which result from the high WSC content. This finding conforms to conclusions that wellfermented silages with high residual sugars and lactic acid are prone to spoil because they can be used as substrates by yeasts (McDonald et al., 1991). Furthermore, the high WSC content appeared to favor high levels of yeast in the resulting silage, as the fermentation of sugars (the only source of energy for yeast under anaerobic conditions) could provide energy to export the $\mathrm{H}^{+}$ions that will reduce the intracellular $\mathrm{pH}$ and kill the cell, thereby, counteract the harmful effect of $\mathrm{H}^{+}$ions on yeast (McDonald et al., 1991; Pahlow et al., 2003). It is similar to the conclusion that yeasts are favored by the addition of formic acid because increased amounts of residual sugars contributed to its survival (Henderson et al., 1972). In our previous laboratory experiments, even longer aerobic stability has been observed in TMR silage with materials other than WCC (Hao et al., 2015). Therefore, the inclusion of WCC in CTMR might contribute to the survival of yeast in this study.

It is common that aerobic deterioration is accompanied by a temperature increase, $\mathrm{pH}$ changes, and an increase in yeast counts. The increase in temperature by $2{ }^{\circ} \mathrm{C}$ above the ambient temperature is mostly adopted to evaluate aerobic deterioration. It has been indicated that the temperature increase in silage is associated with the microbial oxidation of acids and WSC to carbon dioxide and water (Ranjit and Kung, 2000). Results also indicated that the rise in temperature is greater in crops of higher DM concentration than in those of lower DM concentration, because more heat is required to raise the temperature of wetter material than is needed for drier material (Wilkinson and Davies, 2013). This might account for the higher peak temperature in CTMR silages than that of WCC silages during the same ensiling period. In this study, a rise in silage $\mathrm{pH}$ was concomitant with heating, which is attributed to that lactic and other acids can be used as substrate by acid-resistant microorganisms. The metabolism of antifungal organic acids and the increase in silage $\mathrm{pH}$ facilitate the development of other less acid-tolerant aerobic microorganisms (e.g., molds, bacilli) (Woolford, 1990). In addition, the catabolism of protein to $\mathrm{NH}_{3}$ also contributes to the increase in $\mathrm{pH}$ (Rooke and Hatfield, 2003). However, for short-ensiled C-TMR silages, a decline in $\mathrm{pH}$ was observed after it increased to approximately 7.0. The slowly 
decreased lactic acid and increased acetic acid contents (on DM basis) that were probably caused by DM losses in the late deterioration may partly account for the $\mathrm{pH}$ decrease. No other suitable explanation could be made based on the current data. Decreased $\mathrm{pH}$ during deterioration were also reported in silages with high original $\mathrm{pH}$ (higher than 5.0), which presumably because of the restricted fermentation due to high DM contents (Ohyama et al., 1975). However, no $\mathrm{pH}$ decline was observed for the long-ensiled C-TMR silages during exposure. This probably due to the length of deterioration, which was not sufficiently long to reach the peak value, or the fact that no $\mathrm{pH}$ decrease would be observed during exposure.

As indicated by Seppala et al. (2013), a small quantity of sample would increase the rate of heat loss of the sample relative to heat production, thus hindering heat accumulation. Furthermore, the small sample size likely also contributed to the variable results obtained for DM-loss measurements during the aerobic exposure. Approximately $10 \mathrm{~kg}$ of sample were used for aerobic stability test in this study. Therefore, analysis of aerobic deterioration will be more representative. In this study, enhanced aerobic stability was observed in both WCC and C-TMR silages with prolonged ensiling and C-TMR silages were more aerobically stable than WCC silages. Besides, a decreased temperature peak and a compressed heat period were also observed in both silages with prolonged ensiling. In addition to the inhibition of undesirable microorganisms and the differences in characteristics of materials and silages, the microbial diversity also contributed to the differences in aerobic stability of silages. As discussed above, yeast are closely associated with the onset of the aerobic deterioration of C-TMR silage. To clarify the mechanisms underlying the enhancement in aerobic stability and thereby prevent deterioration, further studies on the yeast profiles associated with aerobic deterioration should be performed.

\section{CONFLICT OF INTEREST}

We certify that there is no conflict of interest with any financial organization regarding the material discussed in the manuscript.

\section{ACKNOWLEDGMENTS}

This work was financially supported by the National Natural Science Foundation of China (31172240), the National Scientific and Technological support projects (2011BAD17B02) and the Chinese Universities Scientific Fund (2012YJ100).

\section{REFERENCES}

AOAC. 1990. Offcial Methods of Analysis. 15th Edn. Association of Official Analytical Chemists, Arlington, VA, USA.

Filya, I. 2003. The effect of Lactobacillus buchneri, with or without homofermentative lactic acid bacteria, on the fermentation, aerobic stability and ruminal degradability of wheat, sorghum and maize silages. J. Appl. Microbiol. 95:1080-1086.

Hao, W., H. L. Wang, T. T. Ning, F. Y. Yang, and C. C. Xu. 2015. Aerobic stability and succession of yeasts during deterioration of non-fermented and fermented total mixed ration with different moisture levels. Asian Australas. J. Anim. Sci. 28:816-826.

Henderson, A. R., P. McDonald, and M. K. Woolford. 1972. Chemical changes and losses during the ensilage of wilted grass treated with formic acid. J. Sci. Food Agric. 23:10791087.

Heron, S. J. E., J. F. Wilkinson, and C. M. Duffus. 1993. Enterobacteria associated with grass and silages. J. Appl. Bacteriol. 75:13-17.

Hu, X., W. Hao, H. Wang, T. Ning, M. Zheng, and C. Xu. 2015. Fermentation characteristics and lactic acid bacteria succession of total mixed ration silages formulated with peach pomace. Asian Australas. J. Anim. Sci. 28:502-510.

McDonald, P. 1981. The biochemistry of silage. John Wiley \& Sons, Ltd., New York, NY, USA.

McDonald, P., A. R. Henderson, and S. J. E. Heron. 1991. The biochemistry of silage. 2nd Ed. Chalcombe Publications, Welton, UK.

Nishino, N., H. Harada, and E. Sakaguchi. 2003. Evaluation of fermentation and aerobic stability of wet brewers' grains ensiled alone or in combination with various feeds as a total mixed ration. J. Sci. Food Agric. 83:557-563.

Ohyama, Y., S. Masaki, and S. I. Hara. 1975. Factors influencing aerobic deterioration of silages and changes in chemical composition after opening silos. J. Sci. Food Agric. 26:11371147.

Owens, V. N., K. A. Albrecht, R. E. Muck, and S. H. Duke. 1999. Protein degradation and fermentation characteristics of red clover and alfalfa silage harvested with varying levels of total nonstructural carbohydrates. Crop Sci. 39:1873-1880.

Pahlow, G., R. E. Muck, F. Driehuis, S. J. Elferink, and S. F. Spoelstra. 2003. Microbiology of ensiling. In: Silage science and technology (Eds. D. R. Buxton, R. E. Muck, and J. H. Harrison). American Society of Agronomy, Madison, Wi, USA. pp. 31-93.

Ranjit, N. K. and L Jr. Kung. 2000. The effect of Lactobacillus buchneri, Lactobacillus plantarum, or a chemical preservative on the fermentation and aerobic stability of corn silage. J. Dairy Sci. 83:526-535.

Rooke, J. A. and R. D. Hatfield. 2003. Biochemistry of ensiling. In: Silage Science and Technology (Eds. D. R. Buxton, R. E. Muck, and J. H. Harrison). American Society of Agronomy, Madison, WI, USA. pp. 95-139.

Seppälä, A., T. Heikkilä, M. Mäki, H. Miettinen, and M. Rinne. 2013. Controlling aerobic stability of grass silage-based total mixed rations. Anim. Feed Sci. Technol. 179:54-60.

Smith, L. H. 1962. Theoretical carbohydrates requirement for 
alfalfa silage production. Agron. J. 54:291-293.

Spoelstra, S. F., M. G. Courtin, and J. A. C. Van Beers. 1988. Acetic acid bacteria can initiate aerobic deterioration of whole crop maize silage. J. Agric. Sci. 111:127-132.

Van Soest, P. J., J. B. Robertson, and B. A. Lewis. 1991. Methods for dietary fiber, neutral detergent fiber, and non-starch polysaccharides in relation to animal nutrition. J. Dairy Sci. 74:3583-3597.

Wilkinson, J. M. and D. R. Davies. 2013. The aerobic stability of silage: Key findings and recent developments. Grass Forage Sci. 68:1-19.
Woolford, M. 1990. The detrimental effects of air on silage. J. Appl. Microbiol. 68:101-116.

Xu, C., Y. Cai, N. Moriya, and M. Ogawa. 2007a. Nutritive value for ruminants of green tea grounds as a replacement of brewers' grains in totally mixed ration silage. Anim. Feed Sci. Technol. 138:228-238.

Xu, C. C., Y. Cai, J. G. Zhang, and M. Ogawa. 2007b. Fermentation quality and nutritive value of a total mixed ration silage containing coffee grounds at ten or twenty percent of dry matter. J. Anim. Sci. 85:1024-1029. 